\title{
Aplicação de metodologias científicas e interdisciplina- res nas aulas de botânica no ensino fundamental
}

\author{
Application of scientific and interdisciplinary methodologies in botany classes in elementary school
}

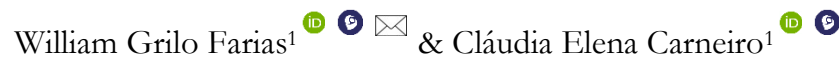

1. Universidade Estadual de Feira de Santana, Departamento de Ciências Biológicas, Feira de Santana, Bahia, Brasil

Palavras-chave:

Pesquisa-ação. Ensino de ciências.

Educação não-formal.

\section{Keywords:}

Action research. Science teaching. Non-formal education.

Recebido em: 02/07/2020

Aceito em: 10/09/2020

Editor responsável: Jaílson S. de Novais (UFSB)

eISBN: 2595-6752

\begin{abstract}
Resumo
No que tange ao ensino de botânica, vários discursos vêm sendo pontuados, caracterizando-o como teórico e descontextualizado. Em contrapartida, os assuntos em educação ambiental recebem grande ênfase no ambiente escolar e em espaços não-formais de educação, como por exemplo, os parques ecológicos. Tendo como estratégia metodológica a pesquisa-ação, objetivou-se refletir com os estudantes a importância da preservação das plantas para o equilibrio ambiental, através da interdisciplinaridade entre botânica e educação ambiental. Como resultado, as atividades realizadas estimularam cada um deles na tomada de decisões e a pensarem estratégias para o desenvolvimento sustentável. E, nesse contexto, a adoção de uma postura ativa e responsável torna-se fundamental numa sociedade em que medidas mitigatórias ainda não são colocadas em prática.
\end{abstract}

\begin{abstract}
Regarding the teaching of botany, several speeches have been punctuated, characterizing it as theoretical and decontextualized. In contrast, subjects in environmental education receive great emphasis on the school environment and non-formal educational spaces, such as ecological parks. Using action research as a methodological strategy, the objective was to reflect with students the importance of preserving plants for environmental balance, through the interdisciplinarity between botany and environmental education. As a result, the activities carried out stimulated each of them in decision-making, and to think about strategies for sustainable development. And, in this context, the adoption of an active and responsible posture becomes fundamental in a society in which mitigation measures are not yet put into practice.
\end{abstract}

Introdução

No que tange ao ensino de botânica na educação básica, nos últimos tempos, vem sendo caracterizado como teórico, no qual o aluno precisa memorizar os conteúdos e conceitos, e assim cria no estudante certo desinteresse em estudá-la. Sobre isso, Melo et al. (2012, p. 2) dizem que despertar o interesse dos alunos pela botânica é um desafio, se as práticas docentes se voltarem apenas para o livro didático e aulas expositivas, sem atentar para a realidade do estudante. Torna-se, então, difícil compreender e associar o estudo das plantas com processos vitais para os seres vivos como, por exemplo, o processo de fotossíntese, resumindo-o à memorização das fórmulas, sem refletir sobre a importância desse processo para evitar a intensificação do efeito estufa. Nesse cenário, Amadeu e Maciel (2014, p. 226) reforçam que essa dificuldade parte tanto do professor, pela falta de materiais 
didáticos, quanto do aluno, quando não compreende bem os conceitos da disciplina, e esses dois fatores fazem com que o ensino e a aprendizagem sejam prejudicados.

Em contrapartida, os assuntos em educação ambiental receberam grande ênfase no ambiente escolar. Promovem reflexões acerca da preservação do meio ambiente e das problemáticas antrópicas ao longo do tempo. Isso ocorre através de práticas, oficinas e apoio de espaços não-formais de educação como, por exemplo, os parques ecológicos. Conforme Macedo e Sakata (2003), são resultantes da era industrial nas cidades. Esses espaços surgem como áreas de lazer geralmente longe dos centros urbanos, passando a ideia de um maior contato com a natureza, maior qualidade ambiental, com uso sustentável, garantindo e mantendo a biodiversidade e os demais atributos ecológicos. Sendo assim, são locais profícuos para o desenvolvimento da educação ambiental, à medida que reflexões sobre a reintegração do ser humano ao meio natural podem ser feitas, apresentando para os estudantes a importância da preservação das espécies florais e faunísticas, e das nascentes dos mananciais, promovendo a ampliação e dinamização dos conteúdos escolares.

A botânica e a educação ambiental são duas áreas que tangenciam e podem ser dialógicas, entretanto, são vistas de formas separadas. Desse modo, a percepção humana adquire também uma característica fragmentada, impossibilitando que se adeque como parte integrante da natureza e, consequentemente, com o meio físico que a cerca, o que é corroborado por Alves (1995), que traz essa fragmentação como um mundo departamentalizado no qual o homem se acostuma a viver. Para além disso, a cultura consumista acarreta ao meio ambiente a curto e longo prazo significativo acúmulo de resíduos sólidos, e uma vez que as plantas fazem parte desse ambiente, elas também serão afetadas por tais impactos em um "efeito dominó" de degradação ambiental. Melo et al. (2012, p.2) dizem que entender a ciência proporciona compreender e prever as transformações da natureza, e os estudos da botânica podem contribuir para compreensão da linguagem da natureza que se manifesta ininterruptamente no cotidiano das pessoas, em prol de melhores condições de vida.

Nessa perspectiva, objetivou-se nessa pesquisa fomentar no aluno do ensino fundamental uma postura crítica, reflexiva e investigativa, referente à importância da preservação das plantas e a sua significância para o equilíbrio ecológico, compreendendo também as relações que se estabelecem entre as espécies, e dessas com o meio, corroborando tanto com a construção social dos alunos, para uma participação ativa e racional na sociedade, como também para a promoção do ensino interdisciplinar, por meio de atividades problematizadoras. Sendo assim, é possível aproximá-los dos procedimentos científicos para não somente memorizar teorias presentes nos livros didáticos, mas entender como essas teorias são formadas. Pavão e Freitas (2008, p.15) citam que "fazer ciência na escola é utilizar procedimentos próprios da ciência como observar, formular hipóteses, experimentar, registrar, sistematizar, analisar, criar... e transformar o mundo". Com isso, o estudante assume uma característica de estudante-pesquisador, familiarizando-o com a pesquisa que geralmente está restrita ao ensino superior, e assim ressalta o prazer e a utilidade da descoberta, formando estudantes aptos a responder às problemáticas do mundo atual e entendedores de como são feitas as hipóteses e as teorias científicas.

\section{Metodologia}

\section{Caracterização da pesquisa e do lócus de estudo}

Durante o período de pesquisa, dois espaços principais foram utilizados para realização das atividades: o primeiro, o Colégio Estadual do Campo Padre Henrique Alves Borges, situado no distrito de Humildes, pertencente ao município de Feira de Santana - Bahia. O segundo espaço, o Parque da Cidade Frei José Monteiro, localizado no mesmo município (Figura 1), foi escolhido pelo fato de, durante a graduação do primeiro autor, no decorrer da disciplina "Avaliação de Impacto Ambiental", ter feito um trabalho diagnóstico sobre a ação antrópica nesse espaço, e também por aspectos logísticos. O projeto de pesquisa foi submetido e aprovado pelo Comitê de Ética em Pesquisa com Seres Humanos da Universidade Estadual de Feira de Santana, sob número CAAE 89189318.9.0000.0053.

Figura 1. Localização do Parque da Cidade Frei José Monteiro Sobrinho e do Colégio Estadual de Campo Padre Henrique Alves Borges, em Feira de Santana, Bahia. Fonte: Vista de satélite, Google Maps (2020).

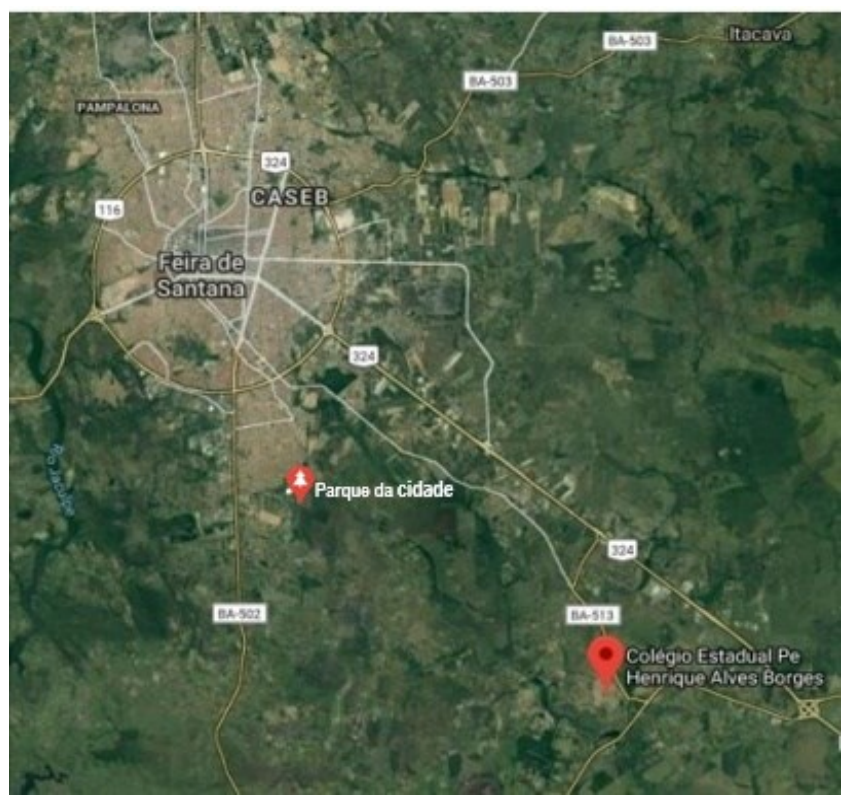

A abordagem da pesquisa refere-se a uma investigação qualitativa do tipo pesquisa-ação. Através da pesquisa qualitativa, os envolvidos ficam mais livres para relatar os seus pontos de vista sobre determinados assuntos que estejam relacionados com o objeto de estudo. Assim, as respostas não são objetivas, e o propósito não é contabilizar quantidades como resultado, mas sim conseguir compreender o comportamento de determinado grupo-alvo. A pesquisa -ação insere-se, conforme Thiollent:

Como uma metodologia derivada da pesquisa social com base empírica, concebida e realizada em estreita associação com uma ação ou a resolução de um problema coletivo, e na qual pesquisadores e participantes representativos da situação ou problema estão envolvidos de modo cooperativo ou participativo (Thiollent, 2011, p.20). 
Voltando-se ao espaço escolar, um local profícuo para a socialização, a pesquisa-ação é fundamentada na coletividade, onde se explora a opinião dos alunos no intuito de repensarem suas atitudes, como também do professor, no que diz respeito à sua prática, como Tripp (2005, p. 445) cita: "A pesquisa-ação educacional é principalmente uma estratégia para o desenvolvimento de professores e pesquisadores de modo que eles possam utilizar suas pesquisas para aprimorar seu ensino e, em decorrência, o aprendizado de seus alunos".

\section{Participantes}

Em um período de Estágio Supervisionado remunerado pelo Instituto Euvaldo Lodi (IEL) e Sistema de Federação das Indústrias do Estado da Bahia (FIEB), o trabalho foi feito com a turma de Ciências do $6^{\circ}$ ano do ensino fundamental, formada por 40 alunos, sendo 23 meninos e 17 meninas, com faixa etária de 10 a 13 anos.

Apesar da mudança curricular proposta pelo Governo Federal desde o ano de 2015, e começo de implementação em 2017, o trabalho foi fundamentado nos Parâmetros Curriculares Nacionais (PCN) vigentes até o ano de 2019 no Estado da Bahia. A pesquisa foi realizada no ano de 2018, e a Base Nacional Comum Curricular (BNCC) foi instaurada somente neste ano de 2020. A escolha da série foi baseada no fato dos alunos estudarem nesse ano letivo o eixo temático Meio Ambiente (Brasil, 1998), e as suas transformações ao longo do tempo, incluindo as interferências antrópicas. Nesse contexto, os objetivos do trabalho tornaram-se melhor compreendidos, visto que os conteúdos presentes na pesquisa já foram apresentados e discutidos com os estudantes, dentre eles a importância e preservação das plantas no meio ambiente, integrando todos os seres vivos que o constituem.

\section{Instrumentos e procedimentos para coleta de dados}

\section{a) Visita prévia à trilha}

Em um primeiro momento, foi realizada uma visita prévia ao parque pelo pesquisador, a fim de melhor definir as estratégias, espécies a serem abordadas durante a trilha e definição do roteiro, observando in loco as possíveis percepções sensoriais relacionadas principalmente ao cheiro que os estudantes pudessem constatar. Gadotti (2000, p.86) cita alguns desses sentidos, como "acariciar uma planta, cheirar um perfume de uma folha de pitanga, de goiaba, de laranjeira... ou de um eucalipto...”.

\section{b) Pré e pós-testes}

No segundo e no quarto momentos, em sala de aula, foram aplicados o pré-teste e o pós-teste, sendo a atividade um cenário hipotético (Material Suplementar); ambos os testes foram respondidos em grupo, antes e após a trilha guiada descrita na próxima subseção. Quatro grupos mistos (meninos e meninas) foram organizados livremente, os quais ficaram responsáveis por pesquisar um tipo de hábito de plantas, respectivamente (árvore, arbusto, erva e trepadeira). Com essa temática, foi possível começarmos as discussões em sala durante a aula sobre a diversidade vegetal, posteriormente observadas durante a trilha.

Os cenários representam uma narrativa contendo alguma questão problema, exigindo do estudante uma tomada de decisão. Nesse sentido, Barbosa e Silva (2010, p.184) discorrem que: “É uma narrativa, textual ou pictórica, concreta, rica em detalhes contextuais, de uma situação de uso da aplicação, envolvendo usuários, processos e dados reais ou potenciais. [...]”. Nesse sentido, um cenário possui uma sequência de ações e eventos: o que os indivíduos fazem, o que acontece com eles, que mudanças ocorrem no ambiente, e assim por diante.

Cada grupo recebeu uma atividade impressa para discutirem entre eles e escreverem sobre o parque hipotético, apresentado em uma sequência de imagens que remetiam aos impactos ambientais causados pelo ser humano e à sua interferência, tanto na flora como na fauna, através dos dispersores de sementes e polinizadores. Essa atividade foi respondida em grupo, como uma forma de, através do diálogo entre eles, chegarem a um consenso sobre a resposta, de acordo com as experiências de cada um, e se posicionarem de forma crítica e reflexiva sobre a problemática.

Com essa atividade, foi possível diagnosticar os conhecimentos prévios dos alunos, o que eles já sabiam, e se houve mudança nas opiniões após a realização das aulas que abordaram temas como polinizadores e dispersores, os quais poderiam ser desconhecidos para os estudantes, como a própria visita ao parque, visto que muitos alunos, mesmo conhecendo esse espaço, poderiam não ter refletido sobre a importância dele na manutenção do equilíbrio ambiental. Nessa perspectiva, Melo et al. (2012, p.5) dizem: "Percebe-se assim, a necessidade de criar atividades que levem ao desenvolvimento do aluno, de seus conceitos, habilidades e atitudes, orientando-os para que eles mesmos consigam alcançar seus objetivos".

\section{c) Trilha guiada e Culminância do projeto}

O terceiro momento foi a realização de uma atividade em campo guiada pelo autor da pesquisa e regente da turma. Durante a trilha no parque, paradas estratégicas foram feitas para explicar aos estudantes sobre a diversidade de plantas e seus hábitos de vida (árvore, arbusto, erva e trepadeira), e sobre a importância desses espaços em nossa sociedade. Cada equipe, organizada anteriormente em sala, anotou as características da planta em questão e foram feitas fotografias das plantas, de animais e do espaço. Com essas fotografias, fizemos uma culminância, na qual foi possível cada grupo compartilhar em roda de conversa o que aprendeu, o que mais gostou de fazer ou o que mais chamou à atenção durante a atividade. Posteriormente, as imagens fotografadas pelos estudantes ficaram disponíveis em uma exposição para toda a comunidade escolar.

A fotografia e a culminância não foram pensadas no préprojeto da pesquisa, elas emergiram ao passo que a proposta foi sendo desenvolvida com os estudantes, o que nos fez refletir sobre a importância de termos um planejamento, mas, também, de reavaliá-lo de acordo com a necessidade e anseios da turma. Isso reforça o que Tripp (2005, p.445) cita sobre a pesquisa-ação como uma estratégia educacional de reavaliação do professor para aprimorar seu ensino e, em decorrência, o aprendizado de seus alunos.

\section{Análise de dados}

A análise de conteúdo e o processo de categorização foram fundamentadas na proposta de Bardin (2011), que apresenta os critérios de categorização, ou seja, escolha de categorias (classificação e agregação). As categorias são rubricas ou classes, as quais reúnem um grupo de 
elementos (unidades de registro, no caso da análise de conteúdo) sob um título genérico, agrupamento esse efetuado em razão dos caracteres comuns destes elementos (Bardin, 2011, p.117).

Diante das respostas dos grupos, as categorias foram elaboradas para melhor compreender e investigar os argumentos elencados pelos estudantes, com palavras ou frases que dialogam entre si, que identificassem o papel das plantas, dos animais, e os impactos antrópicos e as suas interferências na manutenção dos diversos ciclos de vida. Ressalta-se que foi analisada cada uma das respostas coletivas, agrupadas em suas respectivas categorias de acordo com caracteres em comum, referentes ao assunto em questão.

\section{Resultados e Discussão}

No primeiro momento, a visita prévia ao parque teve um caráter autoformativo, tornando-se fundamental para conceber esse aspecto, como uma forma de melhor apropriação do espaço a ser trabalhado, justificando, assim, a importância desse momento para o professor, à medida que começa a fazer o planejamento da proposta pedagógica, ações e estratégias. Nesse contexto, Farias e Silva (2019, p.2815-2816) dizem que a visita prévia (pré-campo) é indispensável para a organização, definição de objetivos, e deve ser adequada ao desenvolvimento cognitivo do aluno, de modo a favorecer a aprendizagem.

Já no segundo e quarto momentos, houve a análise do pré e pós-teste (cenários hipotéticos), aplicados antes e depois da visita ao parque com os estudantes.

\section{Resultados do pré-teste}

Com relação ao cenário hipotético respondido antes da visita ao campo, foram identificadas as seguintes categorias:

\section{a) Causas}

Relacionadas aos possíveis motivos que causam alguns dos problemas ambientais. As interferências humanas sobre a natureza foram apontadas pela maioria dos grupos pelas frases: "Parar de cortar as árvores", "Não é só não jogar lixo nas ruas, temos que também parar de cortar árvores e fazer queimadas nas florestas". Através de tais afirmações, percebe-se que os estudantes se voltam para as ações humanas de desmatamento, queimadas e grande produção de resíduos sólidos, como causadores dos desequilíbrios ambientais. Nesse sentido, Santana (2008) diz que, com a educação ambiental, deve ocorrer o desenvolvimento progressivo de uma postura crítica e sensível, baseada na preocupação ambiental e no entendimento das relações do homem com o ambiente que o cerca.

Outro fator que pode ter corroborado para que os estudantes explanassem tais afirmações é o fato de que esses temas também são os mais falados nas mídias de massa - TV, redes sociais, sites, documentários - que possuem grande influência social e devem ser considerados como uma das formas de aprendizado. Porém, cabe ao professor refletir com os alunos sobre essas informações para que, a partir delas, um posicionamento crítico e coerente seja efetivado.

\section{b) Consequências}

Categoria referente aos impactos ambientais ou socioeconômicos, que foram percebidos nas seguintes frases: "Todos os elementos são finitos", "As árvores são importantes para fazer papel, dinheiro, e produz oxigênio". É sabido pelos estudantes que as causas resultam em eventos que interferem significativamente na dinâmica social e ecológica. Todavia, há nessas duas frases consequências mais relacionadas aos aspectos socioeconômicos do que aos processos ecológicos, relatados apenas pela produção de oxigênio.

Diante disso, surgem fatores relacionados ao desenvolvimento sustentável, ao passo que se precisa utilizar os recursos para atender às necessidades da população, porém, esses recursos podem se esgotar, devendo ocorrer uma reorganização ou ponderação em seu uso. Para Jacobi (2003, p.193), a existência de sustentabilidade social, econômica e ecológica explicita a necessidade de tornar compatível a melhoria nos níveis e qualidade de vida com a preservação ambiental. Nesse cenário, o desenvolvimento sustentável torna-se importante para harmonizar os processos ambientais com os socioeconômicos e, assim, nos insere na natureza para uma ação sociopolítica, ativa e crítica, que priorize e reforce a corresponsabilidade social.

\section{c) Medidas de mitigação}

São as propostas relatadas pelos estudantes para contornar a problemática em questão. Considera-se que existe uma solução para manter um meio ambiente ecologicamente equilibrado, através da inserção dos atores envolvidos nesse ambiente e, assim, ações serem pensadas e concretizadas para resolução diante de uma adversidade. No pré-teste apenas um grupo salientou algo próximo a essa categoria: "Molhar as plantas para não morrer". Sendo um processo fisiológico, a presença de água é importante para o desenvolvimento vegetal, pois, segundo Vieira (2010, p.22) faz o transporte de nutrientes, contribui para a divisão celular, regulação térmica, fotossíntese e transporte de excreções.

Mesmo que não saibam explicar o processo hídrico dos vegetais, é notável a aproximação com o cotidiano desses estudantes, à medida que o hábito de molhar ou regar uma planta é realizado tanto por pessoas que a possuem em casa, quanto nas pequenas lavouras presentes no distrito, e tal prática evita a morte do vegetal. Com isso, apresenta-se como uma ação para a preservação das plantas, aliada a aspectos relacionados à etnobotânica, definida por Rocha et al. (2015, p.67) como o estudo da relação existente entre o ser humano e as plantas e o modo como elas são usadas como recursos e, sendo assim, como se integram os aspectos culturais e ambientais.

\section{d) Articulação com processos ecológicos}

Nessa categoria incluíram-se as frases relatadas pelos estudantes referentes às relações ecológicas entre animais e plantas, sendo de grande importância para a percepção do mundo integrado. Dentre os relatos dos grupos, destacam-se as seguintes frases: "Para que eles não desapareçam, para que eles não entrem em extinção”, “A planta produz o oxigênio, o ar que a gente respira e também abriga vários animais". Os estudantes ressaltaram a importância do parque na preservação desses dois grandes grupos, apresentando possíveis eventos que estariam mais suscetíveis a acontecer sem a presença desse espaço, como o processo de extinção que levaria ao desapare- 
cimento das espécies, interferências nas relações ecológicas e no processo de fotossíntese.

Há uma relação mútua entre esses dois grupos de seres vivos, culminando no processo chamado de coevolução, que ocorre quando duas ou mais espécies afetam a evolução uma das outras, por meio da polinização, dispersão, relações presa-predador e assim também, a nutrição (Entendendo a evolução, 2020). Assim, sem a presença de algum desses grupos, o outro teria seu processo evolutivo comprometido. Tal fato foi relatado por um dos grupos, quando exemplificaram o vegetal como abrigo, e que de fato muitas espécies competem por territórios, inclusive algumas aves que utilizam plantas para fazer ninho antes de sua reprodução. Em sala de aula não foi aprofundado sobre o conceito de coevolução, mas, foram aproveitados os relatos dos alunos para refletir com eles sobre essa integração entre os grupos de seres vivos, objetivando ampliar o conhecimento de cada um, percebendo a importância das espécies para o equilíbrio ambiental e para a manutenção das diversas formas de vida no planeta.

\section{Resultados do pós-teste}

No que diz respeito ao pós-teste (aplicado após a visita ao parque), as mesmas categorias foram analisadas, porém, sob uma perspectiva diferente, no intuito de verificar se houve mudanças nos discursos dos grupos mediante aulas ministradas, e se a visita ao parque da cidade corroborou de alguma forma para uma mudança de postura referente à preservação ambiental, incluindo os seres vivos (Quadro 1).

No que diz respeito à categoria Causa, não houve mudança de discurso. As práticas antrópicas continuam sendo apontadas pelos estudantes como as precursoras das problemáticas ambientais. É sabido que muitos eventos nem sempre estiveram associados ao ser humano, como, por exemplo, as mudanças climáticas. Entretanto, hoje em dia há grande participação humana na intensificação desse processo e de diversos outros. Portanto, é imprescindível essa responsabilização para uma análise crítica das nossas próprias ações diante da natureza e, a partir disso, nossa postura seja readequada ao contexto atual.

Quanto a categoria Consequências, não foram identificadas palavras no relato dos estudantes que entrassem em acordo com o que foi estabelecido na elaboração dessa categoria. Ou seja, em nenhuma das respostas houve resultado, produto ou fenômeno resultante da ação antrópica na natureza.

As categorias Medidas de mitigação e Articulação com processos ecológicos tiveram uma maior quantidade de relatos do que no pré-teste. Segundo Pelicioni (1998, p.22), a educação ambiental deve tornarse uma filosofia de vida, de modo a levar a adoção de comportamentos ambientalmente adequados, transformando-se em ações que contribuam para a construção da cidadania e melhoria da qualidade de vida. Diante disso, o fato de as consequências não terem sido relatadas torna-se um ponto positivo, visto que a conjuntura atual do planeta já se encontra em modificações ambientais que são exatamente essas consequências. Dar grande ênfase a essa categoria poderia nos levar a pouco espaço para debatermos sobre medidas de mitigação, que são propostas pensadas para reverter ou amenizar um determinado evento.

Vale ressaltar que, no pré-teste, apenas um grupo relatou algo próximo ao que caracteriza uma medida de mitigação. Já para esse momento, de forma geral, os grupos apresentaram meios pelos quais podemos diminuir os impactos ambientais, reforçando o papel do parque nesse processo, como um espaço de preservação. Outro fator notado foi o acréscimo de um novo ecossistema, a lagoa, que durante as aulas não teve muito destaque, mas, com a visita ao parque da cidade, os estudantes notaram a sua importância, principalmente por abrigar outras formas de vida.

No que diz respeito à articulação com processos ecológicos, nota-se uma significativa diferença no pós-teste, com relação ao pré -teste, à medida que os estudantes citaram processos que foram discutidos durante as aulas, a exemplo da polinização e dispersão, relatados pela maioria dos grupos. A visita ao parque também colaborou para esse quesito, haja vista as curiosidades que eles tiveram durante a trilha também estarem relacionadas a processos ecológicos como, por exemplo, as diferentes cores do hibisco (Hibiscus L.), que se refere a um gênero de plantas com flores com aproximadamente 300 espécies no mundo, e atualmente têm grande importância econômica. Tal coloração está associada à reprodução, ao tipo de polinizador e ao transporte do pólen.

Quadro 1: Categorias e citações pós-teste relatadas pelos estudantes. Fonte: os autores (2020).

\begin{tabular}{ll}
\hline Categorias & Citações dos estudantes \\
\hline Causas & "O ser humano está desmatando muitas árvores para fazer papel, borracha, portas, janelas, mesas, cadeiras etc." \\
Consequências & Não houve relatos \\
Medidas de mitigação & "Devemos cuidar do parque porque ele abriga diversos tipos de seres vivos, como plantas, animais, e a lagoa" \\
& "Parar de jogar lixo na rua e diminuir o desmatamento" \\
& "São duas palavras cuidar e zelar, se pararmos de jogar lixo mas continuar a por exemplo, faz̧er queimadas estaremos destruindo o lar dos \\
& animais e as plantas" \\
& "Observamos bastante plantas e animais que se alimentam das plantas, polinizadores, formigas, e também o lago que provavelmente tem \\
& animais, e descobrimos que as cigarras quanto mais crescem vão mudando de casca" \\
"Aprendemos sobre uma flor chamada bibisco ela tem vários tipos de cores para chamar atenção dos animais" & "O beija-flor é importante para todo mundo porque ele pega o pólen de uma flor e espalha para as outras e não deixa elas morrerem"
\end{tabular}




\section{Resultados da visita ao Parque}

A visita ao parque da cidade foi o momento mais esperado pelos estudantes, saindo dos muros da escola e indo a campo observar cada um dos elementos naturais presentes nesse espaço. A prática de observação também caracteriza uma vivência científica, pois, por meio desta é que muitos cientistas puderam formular hipóteses e teorias sobre os fenômenos naturais. E, de fato, durante as paradas estratégicas na trilha para falar sobre as espécies de plantas e seus hábitos de vida, muitas foram as observações dos estudantes. Uma delas, logo no início, um dos alunos identificou e demonstrou gostar muito do "pé-de-jambo" ou jambeiro, colocando sobre ele um forte valor sentimental por gostar do fruto e por ter essa árvore em sua casa. Nesse sentido, ao percorrermos a trilha, reforça-se o conceito já citado por Bondía (2002, p.21) sobre experiência, o que nos passa, o que nos acontece, o que nos toca. Em uma trilha, várias sensações podem ser afloradas de acordo com nossa vivência, expressas de forma espontânea.

Os estudantes ficaram muito curiosos e atentos a tudo o que viam durante o trajeto. Um desses momentos foi quando encontraram a casca de uma cigarra agarrada ao tronco de uma árvore (processo de ecdise, em que ocorre a troca de casca que alguns animais fazem ao se desenvolverem). E assim, por meio da própria curiosidade deles, o conhecimento era construído. Para Guimarães (2006, p.7), através das trilhas há um resgate do significado e do valor da interação pessoa-paisagem, entendendo os valores relacionados à proteção e à sensibilização ambiental.

Saber sobre os hábitos de vida das plantas (árvore, arbusto, erva, trepadeira) foi um momento fundamental para o entendimento da diversidade biológica desse grupo, pois, muitas vezes, as diferentes formas de plantas passam despercebidas. Apesar de não ser conteúdo do $6^{\circ}$ ano, o estudo tem potencial para ajudar esses estudantes em anos seguintes para o entendimento da classificação biológica.

\section{Fotografias e culminância}

A ideia das fotografias surgiu quando, em aula antes da visita ao parque, um dos estudantes perguntou se poderia levar o celular para fotografar. Então, não houve orientação para os estudantes sobre quais imagens eles deveriam captar ou como deveriam fotografar. Porém, inserimos essa atividade na pesquisa, primeiro, pela sugestão do estudante e, segundo, porque identificamos potencialidades em retratar e mostrar as diferentes percepções que os estudantes poderiam ter sobre o ambiente estudado, por fotografias tiradas com seus aparelhos celulares. Conforme Oliveira (2016, p.210) "utilizar as tecnologias de forma integrada ao projeto pedagógico é uma maneira de se aproximar da geração do século XXI e que aprende de formas diversas".

Grande parte das fotografias eram selfies (autorretrato), tendo como plano de fundo o espaço físico, árvores frutíferas presentes no parque, a lagoa e pessoas fazendo atividade física. Silva e Aragão (2012, p.54) dialogam que cada indivíduo interpreta o meio em que está inserido de acordo com seus interesses, ou seja, a forma como cada cidadão compreende o espaço e os acontecimentos dos quais participa é estritamente subjetiva. A trilha proporcionou isso pela observação de elementos que podem ter grande relevância socioeconômica ou cultural. De posse dessas imagens, organizei uma exposição fotográfica com os estudantes, selecionando as imagens que foram exibidas em um mural para a comunidade escolar do nosso dia no parque, sendo priorizadas por eles as imagens que mostravam a diversidade vegetal e alguns locais como a lagoa, um viveiro de pássaros e a estufa de plantas nativas.

\section{Considerações Finais}

O ensino de botânica mostra-se nos dias atuais como um dos mais discutidos entre profissionais da área e professores da educação básica, visto que na maioria das aulas a memorização do conteúdo se faz mais presente do que o entendimento por parte dos alunos. As plantas naturalmente fazem parte do nosso cotidiano e é possível, através disso, aproximar os estudantes do conteúdo científico, seja pela utilização econômica, medicinal, religiosa ou nutricional. É preciso que, em âmbito escolar, seja possível o dialogismo entre diferentes disciplinas caracterizando a interdisciplinaridade, e também entre os conteúdos de uma mesma disciplina, a exemplo dos processos de polinização e dispersão, que podem ser melhor compreendidos conhecendo a biodiversidade vegetal e suas respectivas estruturas florais. Da mesma forma, não podemos apresentar tais conteúdos sem refletir sobre o ambiente, nossas ações e impactos causados que afetam nossa própria espécie e os outros seres vivos.

Conclui-se, dessa forma, que é possível ensinar ciências desenvolvendo nos estudantes o espírito cientifico, no qual, a partir da própria curiosidade do aluno, é fomentada a busca por respostas e o entendimento da natureza que o cerca, percebendo a integração existente entre as espécies e o modo como cada uma interage com o ambiente. As atividades realizadas nessa pesquisa tiveram esse propósito e, para além disso, foi possível fugir da memorização dos conteúdos, contribuindo para um ensino em que o professor não seja somente transmissor do conhecimento, mas que ofereça possibilidades para os estudantes serem protagonistas do próprio aprendizado, estimulando-os para uma participação social mitigatória e responsável.

\section{Agradecimentos}

Aos estudantes, pela participação e colaboração, à UEFS e ao Colégio Estadual de Campo Padre Henrique Alves Borges, pelo apoio na proposta.

\section{Financiamento}

Os autores declaram não haver fontes de financiamento a informar.

\section{Contribuições de Autoria}

Conceitualização: WGF, CEC. Curadoria de dados: WGF. Análise formal: WGF. Investigação: WGF, CEC. Metodologia: WGF, CEC. Administração do projeto: WGF. Supervisão: CEC. Validação: CEC. Visualização: WGF, CEC. Redação - rascunho original: WGF. Redação - revisão e edição: WGF, CEC. 
Conflito de Interesse

Os autores declaram não haver conflitos de interesse a informar.

Disponibilidade dos Dados

Os dados integrais analisados durante o estudo atual podem ser fornecidos mediante solicitação justificada ao autor para correspondência.

Conformidade ética

Os autores declaram que seguiram todas as recomendações éticas e legais cabíveis, incluindo obtenção de consentimento prévio informado de participantes, conforme aprovação pelo Comitê de Ética em Pesquisa com Seres Humanos da Universidade Estadual de Feira de Santana, sob número CAAE 89189318.9.0000.0053.

\section{Referências}

Alves D. Sensopercepção em ações de educação ambiental. Brasília, DF: Inep; 1995. (Série Documental: Antecipações; vol 7)

Amadeu SO, Maciel ML. A dificuldade dos professores de educação básica em implantar o ensino prático de Botânica. Rev. Prod. Disc. Educ. Matem. 2014;3(2):225-235.

Barbosa SDJ, Silva BS. Interação humano computador. Rio de Janeiro, RJ: Elsevier; 2010.

Bardin L. Análise de conteúdo. São Paulo, SP: Edições 70; 2011.

Bondía JL. Notas sobre a experiência e o saber de experiência. Rev. Bras. Educ. 2002;(19):20-28. doi:10.1590/S14132478200200010000

Brasil. Secretaria de Educação Fundamental. Parâmetros Curriculares Nacionais: Ciências Naturais. Brasília, DF: MEC/SEF; 1998.

Entendendo a evolução para professores [internet]. Instituto de Biociências da Universidade de São Paulo [acesso em 21 jun 2020]. Disponível em: https://evocite.ib.usp.br/index.html

Farias RC, Silva AS. O trabalho de campo como instrumento para a construção do conhecimento geográfico. In: Straforini R, Canto TS, Amorim RR, organizadores. Anais do $14^{\circ}$ Encontro Nacional de Prática de Ensino de Geografia: políticas, linguagens e trajetórias. 2019 jun 29 - jul 4; Campinas, SP: Unicamp; 2019. p. 2811-2822.

Gadotti M. Pedagogia da Terra. 2. ed. São Paulo, SP: Peirópolis; 2000.

Guimarães STL. Trilhas interpretativas e vivências na natureza: reconhecendo e reencontrando nossos elos com a paisagem. In: Anais do I Congresso Nacional de Planejamento e Manejo de Trilhas. 2006 nov 7-11; Rio de Janeiro, RJ: UERJ; 2006.

Jacobi P. Educação ambiental, cidadania e sustentabilidade. Cad. Pesqui. 2003;118:189-205. doi:10.1590/S01001574200300010000

Macedo SS, Sakata FG, FG. Parques urbanos no Brasil. São Paulo, SP: Edusp; 2003.

Melo EA, Abreu FF, Andrade AB, Araújo MIO. A aprendizagem de botânica no ensino fundamental: dificuldades e desafios. Scientia Plena 2012;8(10):1-7.

Oliveira PSA. Educação e novas tecnologias: reflexões sobre a prática na educação contemporânea. In: Araújo JA, Santos DLJ, Sobrinho RA, organizadores. Educações: novos olhares, velhas demandas. Curitiba, PR: CRV; 2016. p. 203-214.

Pavão AC, Freitas D. Quanta ciência há no ensino de ciências. São Carlos, SP: EdUFScar; 2008.

Pelicioni MCF. Educação ambiental, qualidade de vida e sustentabilidade. Saúde Soc. 1998;7(2):19-31. doi:10.1590/S01041290199800020000

Rocha JA, Boscolo OH, Fernandes LRRMV. Etnobotânica: um instrumento para valorização e identificação de potenciais de proteção do conhecimento tradicional. Interações 2015;16(1): 67 -74. doi:10.1590/15187012201510
Santana AC. Educação ambiental e as empresas: um caminho para a sustentabilidade [internet]. Educação Ambiental em Ação 2008;24 [acesso em 26 nov 2018]. Disponível em: http:// www.revistaea.org/artigo.php?idartigo $=57$

Silva NM, Aragão RF. A observação como prática pedagógica no ensino de geografia. Geosaberes 2012;3(6):50-59.

Thiollent M. Metodologia da pesquisa-ação. São Paulo: Cortez; 2011.

Tripp D. Pesquisa-ação: uma introdução metodológica. Educ. Pesqui. 2005;31(3):443-466. doi:10.1590/S1517-9702200500030000

Vieira EL, Souza GS, Santos AR, Silva JS. Manual de fisiologia vegetal. São Luiz: Edufma; 2010.

Vista de satélite do Parque da Cidade Frei José Monteiro Sobrinho e do Colégio Estadual de Campo Padre Henrique Alves Borges, em Feira de Santana, Bahia, Brasil [mapa na internet]. Feira de Santana, BA: Google Maps; c2020 [acesso em 2020]. Disponível em: https://www.google.com.br/maps/@-12.3012985,$38.9573235,13.7$

\section{Como citar este artigo}

How to cite this article

(ABNT)

FARIAS, W. G.; CARNEIRO, C. E. Aplicação de metodologias científicas e interdisciplinares nas aulas de botânica no ensino fundamental. Paubrasilia, Porto Seguro, v. 4, e0045, 2021. DOI 10.33447/paubrasilia.2021.e0045

(Vancouver)

Farias WG, Carneiro CE. Aplicação de metodologias científicas e interdisciplinares nas aulas de botânica no ensino fundamental. Paubrasilia 2021;4:e0045. doi:10.33447/paubrasilia.2021.e0045

Este artigo possui errata disponível em: https://doi.org/10.33447/ paubrasilia.2021.e0073er

This article has errata available at: https://doi.org/10.33447/ paubrasilia.2021.e0073er

Este artículo tiene errata publicada en: https://doi.org/10.33447/ paubrasilia.2021.e0073er

\section{ERRATA}

No artigo "Aplicação de metodologias científicas e interdisciplinares nas aulas de botânica no ensino fundamental", com número de doi: 10.33447/paubrasilia.2021.e0045, publicado na revista Paubrasilia, 4:e0045, na página 7 do arquivo. Correção na citação do artigo nos modelos ABNT e Vancouver.

onde se lia:

(ABNT)

FARIAS, J. G. (...)

(Vancouver)

Farias JG (...)

leia-se:

(ABNT)

FARIAS, W. G. (...)

(Vancouver)

Farias WG (...) 


\section{Atividade Cenários Hipotéticos}

Olá, sejam bem-vindos ao nosso parque! Ele abriga diversos seres vivos entre animais e plantas que desempenham importantes papeis no nosso ecossistema. Porém, nos últimos tempos nós seres humanos não estamos cuidando da natureza como deveríamos. Sabendo disso, como você pode salvar animais e plantas para que eles não desapareçam?
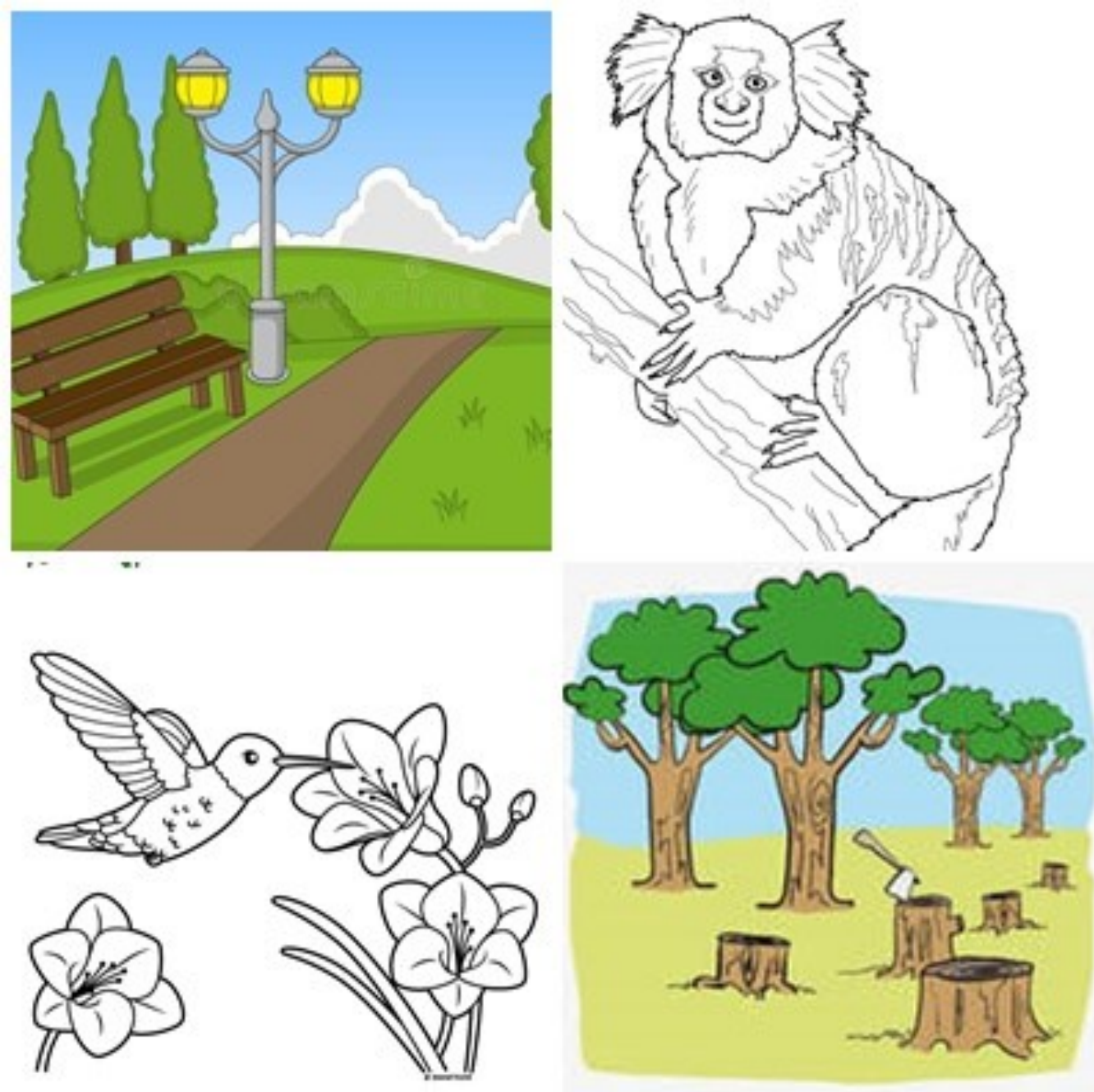